\title{
DCEF/Pr/92521- T/103
}

TECHNICAL REPORT

September 1 through November 30, 1993

\section{Project Title: UPGRADING MILD GASIFICATION LIQUIDS TO PRODUCE ELECTRODE BINDER PITCH}

DOE Grant Number:

ICCI Project Number:

Principal Investigator:

Project Manager:
DE-FC22-92PC92521 (Year 2)

93-1/1.3A-3M

Richard A. Knight, Institute of Gas Technology

Dan Banerjee, Illinois Clean Coal Institute

\section{ABSTRACT}

The objective of this program is to investigate the production of electrode binder pitch, valued at $\$ 250-$ $\$ 300 /$ ton, from mild gasification liquids. The IGT MILDGAS process pyrolyzes coal at $1000^{\circ}-1500^{\circ} \mathrm{F}$ to produce solid, gas, and liquid co-products. With Illinois coal, the $750^{\circ} \mathrm{F}+$ distillation residue (crude pitch) comprises 40-70\% of the MILDGAS liquids, representing up to 20 wto of maf feed coal.

The largest market for pitch made from coal liquids is the aluminum industry, which uses it to make carbon anodes for electrolytic furnaces. In this project, crude pitch from the DOE-sponsored MILDGAS process research program is being modified by a flash thermocracking technique to achieve specifications typical of a binder pitch. A pitch thermocracking unit was constructed for operation at $1200^{\circ}-1800^{\circ} \mathrm{F}$. Reactor design features and process conditions are being examined to optimize the properties of the finished pitch.

During the current quarter, the semi-continuous thermocracking unit was updated with several improvements: pressure transducers, a mass flow controller, and a load cell transducer were installed to improve data acquisition and control capabilities. Also, two samples produced in the previous year were evaluated by a commercial tar processing firm for mesophase content, QI particle size, and other carbon types. They concluded that one of the pitches produced at $1500^{\circ} \mathrm{F}$ is a suitable precursor for electrode binder pitch, while the other was unsuitable, primarily because of degradation occurring during sample workup in the laboratory. The preferred pitch sample contained only 0.4 \& mesophase, and the dispersed QI was mostly primary QI $\left(\alpha_{1}\right.$ resins) of 0.2 to 2 microns diameter.

ATRR

Parametric testing of pitch thermocracking will resume during the next quarter.

DISTRIBUTION OF THIS DOCUMENT IS UNLIMTTED

Notice: U.S. DOE Patent Clearance is NOT required prior to the publication of this document 
The objective of this program is to investigate the production of electrode binder pitch from mild gasification liquids. The IGT mild gasification process, MILDGAS, is low-temperature coal pyrolysis in a fluidized/entrained bed to produce char, gases, and liquids. These co-products are to be upgraded to: form coke for steel making and foundries (from char); fuel gas (from gases); and chemical feedstocks such as BTX and phenols, and industrial pitch binders (from liquids). From the mild gasification liquids, the $750^{\circ} \mathrm{F}+$ distillation residue (crude pitch) comprises 40 to $70 \%$ of the total Iiquid product, representing up to 20 wto of the maf feed coal. Regardless of the production method, crude pitch must be upgraded to meet strict physicochemical specifications for binders.

The largest market for pitch made from coal liquids is the aluminum industry, which consumes $0.45 \mathrm{lb}$ of anode carbon per $1 b$ of aluminum produced. The anodes are typically made by blending 15-35\% hot pitch with a carbonaceous filler (petroleurn coke or pitch coke) and heating to a solid graphitized mass. The anodes are continuously consumed, so the industry needs a steady supply of good-quality pitch and filler. Pitch coke filler, in turn, can be produced by carbonization of coal tar pitch.

In current practice, electrode binder pitch, valued at $\$ 250-$ $\$ 300 /$ ton, is made exclusively from high-temperature $\left(1800^{\circ} \mathrm{F}+\right)$ coke-oven tars. The specifications for binder pitch are written specifically to exclude other materials such as asphalt, unmodified low-temperature coal tars, or even substandard coke-oven tars. A highly aromatic feedstock is required to achieve good physical and chemical. stability in the electrode. Pitches from low-temperature tars have not been regarded as suitable for electrode binders, primarily because of inadequate aromaticity and high heteroatom content which lead to unsuitable rheology, reactivity, and resulting physical properties of the baked electrodes.

However, not much work has been done to modify the structure of low-temperature pitches to achieve the desired properties, primarily because there is no longer a large low-temperature carbonization industry in most industrialized nations where aluminum smelters operate. Conversely, a continuing decline in metallurgical coke production in the U.S. threatens the supply of by-product coal tar pitch for the aluminum industry. Consequently, this effort to investigate methods of modifying mild gasification 
pitch to meet these specifications offers an opportunity for new uses of Illinois coals.

Some of the tar and/or pitch properties that most influence electrode performance are: quinoline insoluble (QI) content, which has an important role in achieving the desired grain structure in the electrodes; toluene insoluble (TI) content, which, like QI, is an indicator of the degree of polycondensation, and is generally regarded as being in correlation with key rheological properties; softening point, a measure of viscosity development in heated pitch; and coking value, the yield of solid coke upon carbonization. A distinction between "primary" and "secondary" QI is also important. Small-particle primary QI is formed prior to pitch condensation in the coke oven, while larger-diameter secondary $Q I$ can be generated by slow heat treatment of a QI-lean pitch. It is likely that the more desirable primary $Q I$ is formed by polycondensation reactions of pitch components in vapor or aerosol droplet form, which dimensionally limits the growth of mesophase spherules.

The process under study in this project is predicated on the benefits of rapid heating of atomized pitch -- flash thermocracking -- to achieve desirable pitch properties. By use of a flash thermocracker, primary QI can be formed simultaneously with dealkylation, dehydration, and aromatization reactions and removal of lower-boiling components from a mild gasification pitch. The results of a previous (1963-1973) U.S. Bureau of Mines study on the upgrading and utilization of low-temperature lignite tars support this conclusion, and form the foundation for the proposed experimental work.

In this project, the upgrading of a crude pitch fraction from the DOE-sponsored MILDGAS process research unit (PRU) program was studied. The test material was recovered from PRU tests with Illinois No. 6 coal in April-May, 1990. This material was modified by flash thermocracking to increase aromaticity, remove alkyl and heteroatomic substituents, and achieve typical physical property specifications for a binder pitch. A thermocracking unit was constructed and operated at temperatures of $1200-1500^{\circ} \mathrm{F}$ under low-pressure inert gas. An atomizing nozzle was used to disperse the test liquid into droplets of approximately 10-100um in diameter, to limit the formation of secondary $Q I$ (mesophase). The reactor design and flow conditions were selected to minimize contact with the hot reactor walls which results in coke formation. 
In this program, tests are being conducted to determine the effects of temperature, crude pitch feed rate, gas atmosphere, and atomization on product yield and quality. cracked pitch samples are being evaluated for density, softening point, coking value, QI, TI, ash, and elemental analysis. The yields of cracked pitch, coke, oils, water, and fuel gas are determined from material balances. During the previous year, six successful thermocracking tests were performed on an Illinois No. 6 crude pitch.

During the current quarter, several improvements to the semi-continuous thermocracking unit were pursued. A mass flow controller was installed to control and monitor the flow of carrier gas to the reactor nozzle. Pressure transdivers were installed in two locations: in the pitch feed line upstream of the nozzle, and at the outlet of the hot pitch trap downstream of the reactor. A load cell (strain gauge) transducer was installed to continuously monitor the weight of the feed material. All of these instruments have the capability to output continuous data to an on-line recorder.

Microscopic analyses of two samples produced in the previous year were performed by a commercial tar processor, Reilly Industries, Inc., who is also an advisor to IGT on this project. The samples were from tests PC-0209-101 and PC0402-101. Both samples were produced at $1500^{\circ} \mathrm{F}$ with atomization, but the latter sample was produced at a higher crude pitch feed rate. The PC-0209-101 sample apparently experienced some degradation in the sample recovery and workup procedure, as described in a previous quarterly report, and this was reflected in the Reilly report, which suggested that excessive coking and some oxidation took place. However, the PC-0402-101 sample showed very encouraging properties. The mesophase content was very low at only $0.4 \%$, the solid phase consisted predominantly of primary $O I$ ( $\alpha_{1}$-resins), and the QI particle size was mostly 0.2 to 2 microns. Reilly concluded that this sample would be of interest to them as an electrode binder precursor.

In the next quarter, thermocracking tests will resume on the Illinois No. 6 crude pitch. Parameters tested will include temperature, atomization, pitch feed rate, and gas atmosphere. 


\section{OBJECTIVES}

The ultimate goal of this project is to develop a method for thermal cracking of MILDGAS crude pitch to produce an electrode binder pitch. This includes determination of the operating conditions of temperature, crude pitch feed rate, gas atmosphere, and atomization of the crude pitch that yield a suitable specification-grade electrode binder pitch. Treated pitch samples are to be evaluated in terms of density, softening point, coking value, quinoline insolubles (QI), toluene insolubles (TI), mesophase content, ash, and elemental analysis. Material balances will be obtained to determine the yields of cracked pitch, pitch coke, gases, and oils.

The task structure of the current year is as follows:

Task 1. Sample Preparation

Task 2. Equipment Construction and Shakedown

Task 3. Pitch Thermocracking Tests

Task 4. Electrode Preparation and Testing

Task 5. Product Characterization and Testing

Task 6. Data Analysis and Interpretation

Task 7. Process Scale-Up Design

\section{DISCLAIMER}

This report was prepared as an account of work sponsored by an agency of the United States Government. Neither the United States Government nor any agency thereof, nor any of their employees, makes any warranty, express or implied, or assumes any legal liability or responsibility for the accuracy, completeness, or usefulness of any information, apparatus, product, or process disclosed, or represents that its use would not infringe privately owned rights. Reference herein to any specific commercial product, process, or service by trade name, trademark, manufacturer, or otherwise does not necessarily constitute or imply its endorsement, recommendation, or favoring by the United States Government or any agency thereof. The views and opinions of authors expressed herein do not necessarily state or reflect those of the United States Government or any agency thereof. 


\section{INTRODUCTION AND BACKGROUND}

Coal tar pitch is used extensively as a feedstock for the production of binding agents employed in carbon and graphite electrodes. The electrodes, composed of approximately $70 \%$ coke or graphite filler, $30 \%$ binder, and small amounts of lubricants, impregnating agents, or other additives, are consumed in electrolytic smelting of aluminum and steel. The binder serves to plasticize the blend and to cement the solid carbon particles during the carbonization (or graphitization) process. To qualify as electrode binder, the pitch must be a thermoplastic material capable of thoroughly wetting and cementing the filler particles. In addition, the carbonization or graphitization process must result in a high coke yield for the binder.

The largest market for pitch made from coal liquids is the aluminum industry, which consumes $0.45 \mathrm{lb}$ of anode carbon per $1 b$ of aluminum produced. The next largest existing market is roof binders, which compete successfully with petroleum-based bitumens, but do not command the premium price of electrode pitch. There are other markets for pitch, but these are relatively small and geographically scattered.

In current practice, electrode binder pitch is made exclusively from high-temperature $\left(1800^{\circ} \mathrm{F}+\right)$ coke-oven tars. The specifications for binder pitches are written specifically to exclude other materials such as asphalt, unmodified low-temperature coal tars, or even substandard coke-oven tars. A highly aromatic feedstock is required to achieve good physical and chemical stability in the electrode. Low-temperature tar pitches have not been regarded as suitable for direct use as electrode binders, primarily because of inadequate aromaticity and high heteroatom content which lead to unsuitable rheology, reactivity, and resulting physical properties of the baked electrodes.

However, few efforts have been made to modify the chemical and macromolecular structure of low-temperature pitches to achieve the desired properties, primarily because there is no longer a large low-temperature carbonization industry in most industrialized nations where aluminum smelters operate. However, a continuing decline in metallurgical coke production threatens the supply of by-product coal tar pitch for the aluminum industry. Consequently, this effort to investigate methods of modifying mild gasification pitch to meet these specifications offers an opportunity for new uses of Illinois coals. 
Mild gasification is an advanced coal carbonization process that emphasizes simple reactor and process design and lowseverity processing conditions to bring a slate of valueadded co-products (char, fuel gas, and oils/tars) to the marketplace. With support from the U.S. DOE, a project team consisting of Peabody Holding Company, Bechtel National, and IGT has completed a technology development program including the design, construction and operation of a $100-1 \mathrm{~b} / \mathrm{h}$ PRU. 1, 2, 3,4 The MILDGAS reactor consists of a coaxial fluidized-bed/entrained-bed vessel which can process all types of coals. IGT has completed 47 MILDGAS tests on four coals in the PRU, at temperatures ranging from $1034^{\circ}$ to $1390^{\circ} \mathrm{F}$. IGT is currently participating with Kerr-McGee Coal Corporation in the design, construction, and operation of a 24-ton/day MILDGAS process development unit (PDU) at the Coal Development Park operated by Southern Illinois University at Carbondale.

Binder pitch for electrodes used in the aluminum industry has a high market value (over $\$ 300 /$ ton), and the market is large enough to absorb a new source of raw material. However, it is necessary to modify the tars produced in the MILDGAS process to make them suitable for this use. Currently, to fulfill this need, the MILDGAS design calls for the addition of a thermal cracker to the hot effluent gas stream from the gasifier. However, if the thermal treatment is performed on the condensed liquids rather than on the entire effluent stream, the amount of material handled will be reduced by over 508. This will reduce the heat load for the thermal cracker, lowering capital and operating costs of the process.

Some of the tar and/or pitch properties that most influence electrode performance are:

- Quinoline insoluble (QI) content -- this portion of the pitch has an important role in achieving the desired grain structure in the electrodes. There is also an

1 Wootten, J.M., et al., Task 1 Topical Report to DOE/METC, Contract No. DE-AC21-87MC24266, (August 1988).

2 Knight, R.A., et al., Task 2 Topical Report to DOE/METC, Contract No. DE-AC21-87MC24266, (July 1990).

3 Carty, R.H., et al., Task 3 Topical Report to DOE/METC, Contract No. DE-AC21-87MC24266, (December 1990).

4 Knight, R.A., et al., Task 4 Topical Report to DOE/METC, Contract No. DE-AC21-87MC24266, (December 1990). 
important distinction between "primary" and "secondary" QI, also designated $\alpha_{1}$ - and $\alpha_{2}$-resins. Primary $Q I\left(\alpha_{1}\right)$

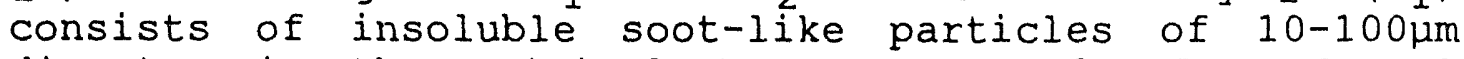
diameter in the original tar. A level of 8-12 wto primary $Q I$ in the pitch is considered desirable. Secondary $Q I\left(\alpha_{2}\right)$ comes from heating the molten pitch to promote further cracking/condensation, forming spherical "mesophase" particles. Excessive amounts of coalesced mesophase adversely affects the rheology and wetting properties of the pitch. 5 Mesophase should comprise no more than about $10 \%$ of the total QI, and the primary QI should be predominantly smaller than $4 \mu \mathrm{m}$ in diameter.

- Toluene insoluble (TI) content -- this portion of pitch, like QI, is an indicator of the degree of polycondensation, and is generally regarded as being in correlation with key physicochemical properties. A TI value of 26348 is typical for a specification anode pitch. TI which are quinoline-soluble are also designated as $\beta$-resins. 5

- Softening point -- this is a measure of viscosity development in heated pitch. A good electrode binder pitch should have a softening point of $190^{\circ} \mathrm{F}$ or higher.

- Coking value -- this is the yield of solid coke upon carbonization. The coking value for a good binder pitch should be $60 \%$ or higher.

Pitch consumers will reject a pitch that has excessive secondary $Q I$. It is likely that the more desirable primary QI is formed by polycondensation reactions of pitch components in vapor or aerosol droplet form, which dimensionally limits the growth of mesophase spherules. By achieving rapid heating of small droplets of pitch in a flash thermocracker, primary QI can be formed simultaneously with dealkylation, dehydration, and aromatization reactions and removal of lower-boiling components from the pitch. The results of a previous U.S. Bureau of Mines study on the upgrading and utilization of low-temperature lignite tars

5 Jütgen, H., J. Klein, K. Knoblauch, H, Schroter, and J. Schulze, Ch. 30 in Chemistry of Coal Utilization, Second Supplementary Volume, John Wiley \& Sons, New York, 213135, (1981). 
over 1963-73 support this conclusion, and form the foundation for the proposed experimental work. $6,7,8,9$

The current project aims to: investigate the effects of rapid thermal cracking of atomized MILDGAS crude pitch; determine the operating conditions of temperature, pitch feed rate, gas atmosphere, and atomization required to produce a pitch with adequately increased QI, TI, softening point, and coking value to qualify as electrode binder pitch; and determine the yields of cracked pitch and other by-products such as coke, oils, and fuel gas.

6 Berber, J.S., R.L. Rice, and J.D. Spencer, U.S. Bureau of Mines Bulletin 663 (1973).

7 Berber, J.S., R.L. Rice, and D.R. Fortney, ACS Div. of Fuel Chem. Prepr. 11:2, 366-377 (1967).

8 Berber, J.S. and R.L. Rice, ACS Div. of Fuel Chem. Prepr. $12: 4,51-62$ (1968).

9 Rice, R.L., D.R. Fortney, and J.S. Berber, ACS Div. of Fuel Chem. Prepr. 13:1, 122-129 (1969). 


\section{EXPERIMENTAL PROCEDURES}

Task 1. Sample Preparation

The mild gasification test liquid (crude pitch) to be used in this project was produced in the IGT MILDGAS process research unit (PRU), during a previous U.S. DOE project, in April-May, 1990. The parent coal was Illinois No. 6 seam coal from Peabody's Baldwin No. 1, Marissa, and River King No. 6 mines. The effluent oils/tars were collected in a xylene quench tower and subjected to a preparative distillation to remove solvent and low-boiling components up to approximately $500^{\circ} \mathrm{F}$. The resultant crude pitch is a solid at room temperature.

The materials from three MILDGAS tests (IST-5, IST-7, and IST-9) were combined to yield a 20-1b composite sample. These three PRU tests were all operated at nearly identical conditions of $1110 \pm 5^{\circ} \mathrm{F}, 10 \mathrm{psig}, 11 \pm 2 \mathrm{~min}$ solids residence time, in a $100 \%$ nitrogen atmosphere. The feedstock was a $1: 1(w / w)$ mixture of Illinois No. 6 coal and recycled char from previous PRU tests.

Because of the availability of the MILDGAS crude pitch from the PRU, IBCSP coal samples are not being used in this program. The coal used to produce the test samples was an Illinois No. 6 coal similar to IBC-101.

The composite test liquid will be characterized according to the methods outlined in Task 5 to evaluate any changes that have taken place during storage.

Task 2. Equipment Construction and Shakedown

The pitch thermocracking test unit consists of a heated sample feed tank, a heated gear pump, an atomizing nozzle, a vertical tubular reactor, a pitch receiver vessel, and a condensing train. A flush tank is also installed to flush the pump and reactor system with solvent following the tests. The atomization of the hot crude pitch with a conventional two-phase spray nozzle requires a carrier gas delivery system. Advanced types of atomizers which do not require large amounts of carrier gas would be available for commercial use, but are beyond the scope of the present program.

The thermal cracker, fabricated from 316 stainless-steel nominal 2-inch Sch40 pipe, is heated by external electrical heaters. The carrier/purge gas system sweeps reaction 
products from the reactor with inert gas. The atomizing nozzle provides good dispersion of the sample in the form of very small droplets with a controlled particle size distribution. The nozzle is designed to produce a narrow stream of atomized sample droplets in laminar flow, which minimizes contact with the hot walls, thus minimizing coke formation and limiting mesophase particle growth. In tests without atomization, the atomizing nozzle assembly is replaced an inlet assembly consisting of coaxial 1/4-inch and $1 / 2-$ inch $316 \mathrm{SS}$ tubes.

A simplified schematic diagram of the thermocracker test unit, prior to the improvements installed during the current quarter, is shown in Figure 1.

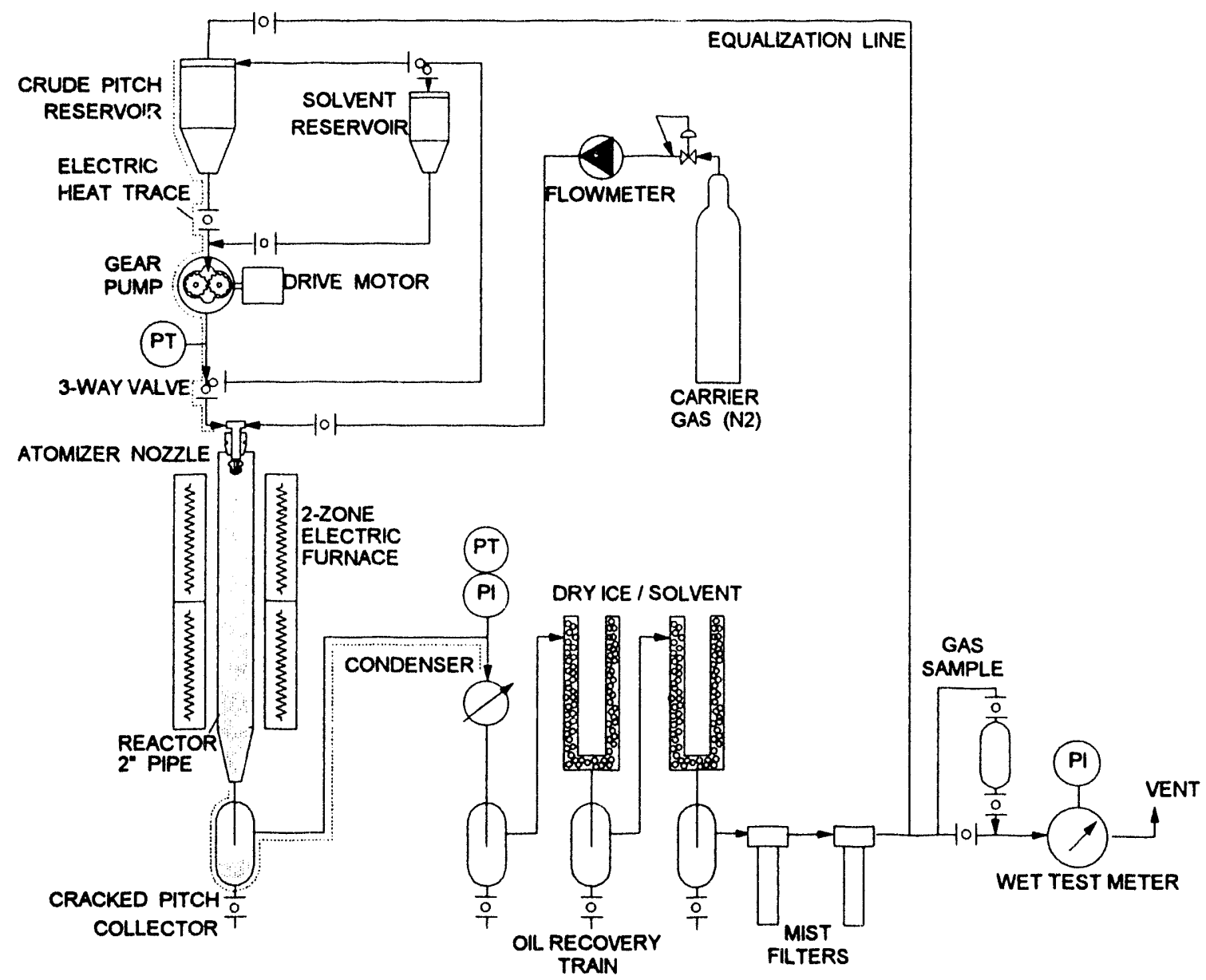

Figure 1. SCHEMATIC DIAGRAM OF EXPERIMENTAL PITCH THERMOCRACKING SYSTEM 
Several minor but important improvements are to be installed in the current program:

- A high-capacity (105 scfh) mass flow controller to maintain a constant carrier gas velocity regardless of transient pressure changes,

- A pressure transducer to monitor the pitch pressure between the pump and nozzle

- A pressure transducer to monitor reactor outlet pressure, and

- A load cell (strain gauge) system to monitor and record the weight of the feed material, in order to directly compute the crude pitch feed rate.

Task 3. Pitch Thermocracking Tests

Approximately 12 thermocracking tests are to be conducted to examine the effects of cracking temperature, pitch residence time, gas atmosphere, and pitch feed rate on product quality and yield. Tests may also be performed with and without the use of the atomizing nozzle to confirm its effectiveness in promoting more thorough cracking of the pitch and production of primary $Q I$, and also in controlling the amount of coke formation. Gas atmospheres to be used include nitrogen and a simulated hydrogen-rich recycled MILDGAS product gas (258 $\left.\mathrm{H}_{2}, 5 \% \mathrm{CO}, 5 \% \mathrm{CO}_{2}, 65 \% \mathrm{CH}_{4}\right)$. All tests will be conducted at minimum sustainable pressure up to a maximum of 20 psig.

In a typical test operation, the system is purged with inert gas, and crude pitch is heated to a temperature of adequate fluidity, about $220^{\circ} \mathrm{F}$, in the feed tank. The hot pitch is pumped via the heated gear pump into the reactor through the atomizing nozzle or inlet tube assembly, along with the preheated carrier/purge gas. Thermal cracking occurs as the pitch fog moves down the 48 -inch length of the reactor. A portion of the cracked pitch and coke collects in the receiver, and the remaining pitch, lower-boiling liquids, and water collects in the condensing train. A solvent consisting of dichloromethane and tetrahydrofuran (THF) is injected at the condensing train inlet to prevent obstruction of the inlet by buildup of carryover pitch at the point where the stream temperature drops rapidly.

After cooling the reactor, cracked pitch and coke are removed from the reactor and receiver. Residues are removed from collector surfaces by immersing in liquid nitrogen and scraping or brushing out the embrittled materials. Pitch is then separated from pitch coke by heating to about $200^{\circ}$ - 
$250^{\circ} \mathrm{F}$ to liquefy the pitch and filtering the coke/pitch through a stainless-steel mesh with a pore opening of $103 \mu \mathrm{m}$.

The condensed solvent/oil/pitch from the condensing train is filtered to recover carryover coke fines. The solvent is removed by rotary vacuum evaporation, the evaporator residue is vacuum-distilled to $750^{\circ} \mathrm{F}$, and the pitch residue is combined with the cracked pitch recovered from the receiver and with the filtered coke fines. The remaining oils are characterized and stored for later disposal.

\section{Task 4. Electrode Preparation and Testing}

The most direct method of evaluating potential performance of a binder pitch is the fabrication and evaluation of test electrodes. Ground pitch is mixed with a filler (petroleum coke or pitch coke) in a fashion designed to ensure wetting of the filler by the binder. The paste is then transferred to a preheated stainless-steel 1.25-inch $\times 5$-inch mold and baked in a nitrogen-purged furrace. The baking conditions are $90^{\circ} \mathrm{F} / \mathrm{h}$, final temperature $1850^{\circ} \mathrm{F}$, total duration 24 hours. The electrode is then slowly cooled and submitted to physical and electrical tests.

The pitch and coke products with the most suitable characteristics are selected for electrode fabrication. The selected pitch coke is calcined (carbonized) in a muffle furnace under nitrogen at $2500^{\circ} \mathrm{F}$ prior to use as an electrode filler. Duplicate test electrodes are to be prepared with conventional and laboratory-prepared ingredients.

Task 5. Product Characterization and Testing

The crude and cracked pitches are to be characterized at IGT by means of the following analyses:

- Quinoline insolubles (ASTM D2318)

- Toluene insolubles (ASTM D4312)

- Softening point, Ring-and-Ball (ASTM D97)

- Coking value (modified ASTM D2416)

- Elemental compposition (modified ASTM D3178)

- Specific gravity (ASTM D70) 
In addition, Reilly Industries will perform the following analyses on selected samples:

- Mesophase content, texture, and carbon type by microscopic point counting technique.

- Distillation (ASTM D86)

- Aromaticity (IR index)

- Major chemical components (GC/MS)

Proximate and ultimate analyses of "green" (e.g., not calcined) pitch coke are to be performed for all successful tests, and some selected calcined pitch coke will be similarly characterized. In addition, GC/MS analysis of the oils recovered from the condenser and the product gases are to be performed on selected samples.

Test electrodes prepared in Task 4 are to be subjected to a series of tests and analyses, including:

- Real and baked apparent density

- Resistivity

- Flexural strength

- Compression strength

- Young's modulus

- Coefficient of thermal expansion (CTE)

- Fracture energy

- Thermal conductivity

- Air permeability

- $\mathrm{CO}_{2}$ reactivity

- Air reactivity

- Elemental analysis (including $\mathrm{F}, \mathrm{S}, \mathrm{V}, \mathrm{Ni}, \mathrm{Si}, \mathrm{Fe}, \mathrm{Al}$, $\mathrm{Na}, \mathrm{Ca}, \mathrm{K}, \mathrm{Mg}, \mathrm{Cl}, \mathrm{Zn}, \mathrm{Pb}, \mathrm{P}, \mathrm{Ti}$, and $\mathrm{Ba}$ )

Task 6. Data Analysis and Interpretation

The primary goal of these experiments is to build a data base on thermocracking of mild gasification pitch made from Illinois No. 6 coal that can be used as a basis for process design and scale-up.

The principal data relevant to the project objectives are: 
- Material balance data for conversion of crude pitch to binder-quality pitch, pitch coke, by-product oils, water, and fuel gas

- Increases in softening point, density, primary QI, TI, coking value, and $\mathrm{C} / \mathrm{H}$ atomic ratio without excessive development of mesophase

- Decreases in heteroatom (N, S, and O) content

- Physical and electrical properties of test electrodes made from the thermally cracked pitch product, aimed at maximizing density, strength, and thermal conductivity, and minimizing resistivity, CTE, permeability, and reactivity.

The thermocracking data are presented in terms of: pitch conversion as a function of temperature, crude pitch feed rate, and atomization; and percent approach to each key property specification as determined by test data on a commercial pitch sample. Crude pitch feed rates are also correlated with estimated residence times.

Task 7. Process Scale-Up Design

The test data, especially material balances, will be used as a basis for a block flow design of flash thermocracking for mild gasification pitch. The current mild gasification PDU design developed in an ongoing DOE/METC-sponsored program will be used as a backdrop for a conceptual integrated pitch cracking operation. The preferred process conditions to obtain a specification-grade binder pitch will dictate the energy balances. The material and energy balances thus derived will be used to produce a block flow diagram of the process integrated with mild gasification. The implications of the design for demonstration and commercial-scale plant design will also be discussed. Reilly Industries will review and comment on the block flow diagram and material and energy balances before they are finalized at the end of the program. 


\section{RESULTS AND DISCUSSION}

Task 1. Sample Preparation

No work was performed in this task during the current quarter.

Task 2. Equipment Construction and Shakedown

The equipment items and parts required for the improvements discussed in the previous section were specified, procured, and installed during the current quarter, with the exception of the load cell, which was procured but not yet installed. The items installed are listed and described below:

\begin{tabular}{|c|c|}
\hline Mass flow controller & $\begin{array}{l}\text { Omega FMA-773-V, } 0-50 \\
\text { sI/min nitrogen, } 40 / 20 \\
\text { psig, ambient, } 0-5 \text { VDC } \\
\text { output }\end{array}$ \\
\hline $\begin{array}{l}\text { Pitch pressure sensor } \\
\text { (pump-nozzle) }\end{array}$ & $\begin{array}{l}\text { Omega PX212-0608V, } 0-60 \\
\text { psig, mV output }\end{array}$ \\
\hline $\begin{array}{l}\text { Pressure sensor (reactor } \\
\text { exit gas) }\end{array}$ & $\begin{array}{l}\text { Omega PX212-0608V, } 0-60 \\
\text { psig, mV output }\end{array}$ \\
\hline $\begin{array}{l}\text { Load cell for crude pitch } \\
\text { reservoir }\end{array}$ & $\begin{array}{l}\text { Omega LCCA-50 s-beam } \\
\text { tension/Compression load } \\
\text { cell, 50-1b capacity }\end{array}$ \\
\hline
\end{tabular}

other minor testing and reconditioning of existing instruments, including temperature controllers and recorders, were performed.

Task 3. Pitch Thermocracking Tests

No work was performed in this task during the current quarter.

Task 4. Electrode Preparation and Testing

No work was performed in this task during the current quarter. 
Task 5. Product Characterization and Testing

Microscopic analyses of two samples produced in the previous year were performed by a commercial tar processor, Reilly Industries, Inc., who is also an advisor to IGT on this project. The samples were from tests PC-0209-101 and PC0402-101. Both samples were produced at $1500^{\circ} \mathrm{F}$ with atomization, but the latter sample was produced at a higher crude pitch feed rate $(11.1 \mathrm{~g} / \mathrm{min}$ versus $2.6 \mathrm{~g} / \mathrm{min})$.

Here is a partial transcript of the Reilly report:

Pitch sample PC-0402-101 was pulverized and heated to about $120^{\circ} \mathrm{C}$ and cast in a cylindrical ring munt, then ground and polished. A total of 1000 points were counted on sample PC-0402-101.

Pitch sample PC-0402-101 consists of 62.38 of continuous binder phase with 37.38 of solids and only 0.48 of mesophase. The solids are unusually abundant and are predominantly normal or natural QI. They are mostly rounded and 0.2 to about 2 microns in diameter. About 4.68 of the 37.38 of solids exceeds 2 microns and only 0.88 of these are coarse. The coarse solids are mostly elongate flakes of spherical aggregates. These flakes or skins are about 7 to 18 microns thick. There are no significant occurrences of coal related solids such as coal, coke, or cenospheres in the sample. There are some areas of concentrated solids that are not dispersed like normal QI.

Pitch sample PC-0402-101 would be of interest to Reilly Industries as a precursor to an electrode binder. Pitch sample PC-0209-101 would be of little interest.

The PC-0209-101 sample apparently experienced some degradation in the sample recovery and workup procedure, as described in a previous quarterly report, and this was reflected in the Reilly report, which suggested that excessive coking and some oxidation took place. However, the PC-0402-101 sample showed very encouraging properties. The mesophase content was very low at only $0.4 \%$, the solid phase consisted predominantly of primary $Q I$ ( $\alpha_{1}$-resins), and the QI particle size was mostly 0.2 to 2 microns.

Figure 1 is a photomicrograph of PC-0402-101, showing the dispersion of primary QI in the binder phase. Table 1 shows Reilly's material category breakdown for the PC-0402-101 sample. 


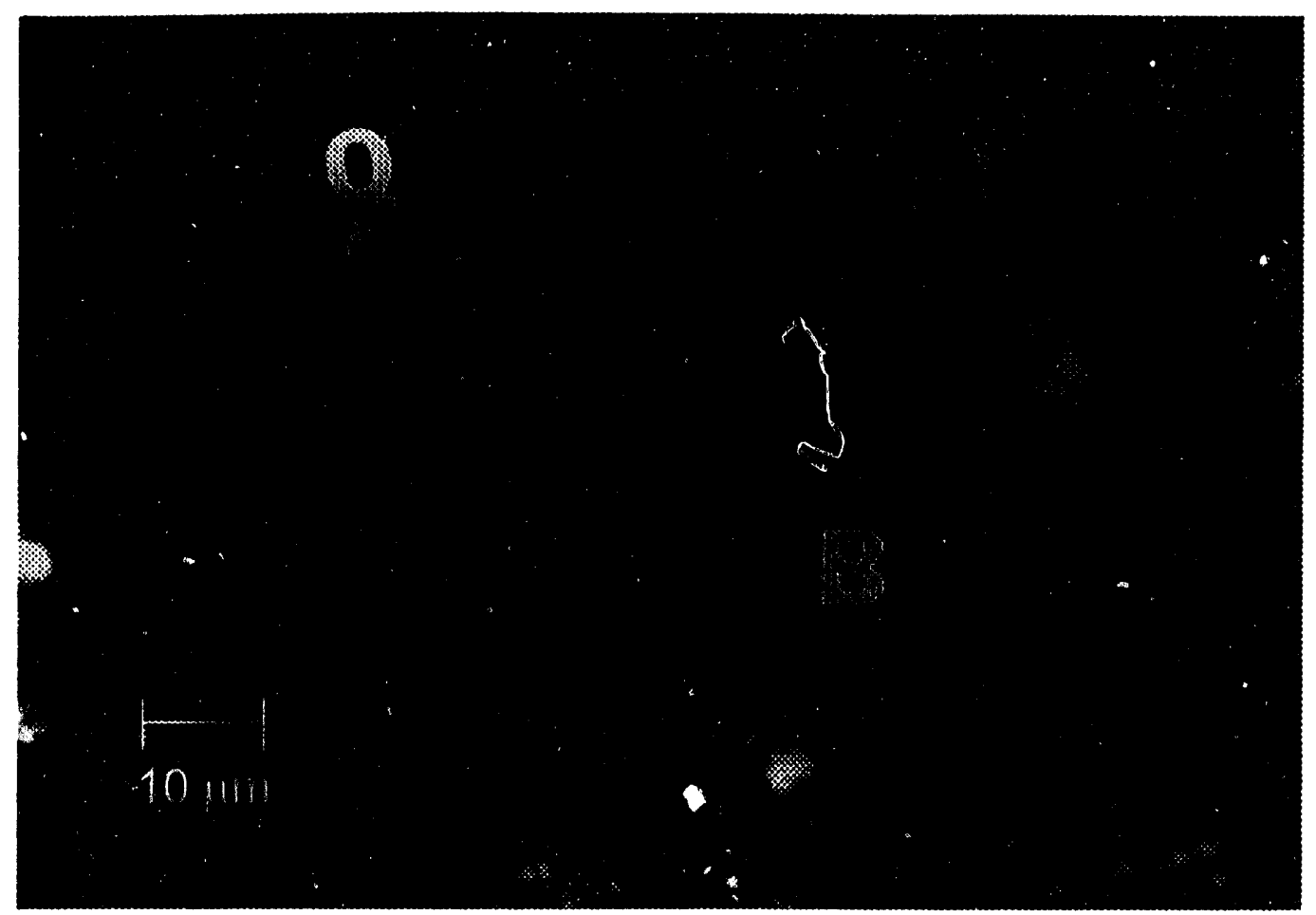

Figure 1. PHOTOMICROGRAPH OF PC-0402-101 CRACKED PITCH

Table 1. CARBON CLASSIFICATION FOR PC-0402-101 CRACKED PITCH

\begin{tabular}{lr} 
Material Categories & Volume $\frac{8}{6}$ \\
\hline Continuous binder phase & 60.8 \\
Embryonic binder phase & 1.5 \\
Primary QI & 33.9 \\
QI in embryonic aggregates & 2.6 \\
Coarse QI & 0.8 \\
Mesophase & \\
$\quad-4$ microns & 0.4 \\
$\quad 4-10$ microns & -- \\
$\quad 10$ microns & --
\end{tabular}

Also during the current quarter, two more samples were submitted to Reilly Industries for microscopic examination. These are product pitches from tests PC-0427-510 and PC0513-511, both of which were conducted at $1400^{\circ} \mathrm{F}$. The main difference between these samples is that PC-0427-510 was produced without the atomizing nozzle, while PC-0513-511 was produced with atomization. 
The results from Reilly on these latter samples have not yet been obtained.

Task 6. Data Analysis and Interpretation

No new samples were generated in the current quarter, but Reilly's analyses of previously produced samples are of interest. The extremely high softening point $\left(273^{\circ} \mathrm{F}\right)$ of the PC-0209-101 pitch had previously suggested that mesophase formation may have occurred. There is a strong possibility that this occurred from excessive heating in contact with air during sample workup. The sample handling procedures was at that time reviuwed and modified to minimize extended heating of the samples from subsequent tests. The Reilly report is consistent with these observations. 


\section{CONCLUSIONS AND RECOMMENDATIONS}

The evaluation by Reilly Industries of a previously produced thermocracked mild gasification pitch adds support to the encouraging results reported for the first year of this project. Microscopic examination of the pitch shows minimal mesophase formation and a predominance of primary QI with particle sizes of smaller than 4 microns.

Equipment improvements are nearly complete, and pitch thermocracking tests will resume during the next quarter.

This work was prepared with the support, in part, by grants made possible by the Illinois Department of Energy and Natural Resources through its Coal Development Board and Illinois Clean Coal Institute, and by the U.S. Department of Energy. However, any opinions, findings, conclusions, or recommendations expressed herein are those of the author(s) and do not necessarily reflect the views of IDENR, ICCI, and the DOE. 
PROJECT MANAGEMENT REPORT

September 1 through November 30, 1993

Project Title: UPGRADING MILD GASIFICATION LIQUIDS TO PRODUCE ELECTRODE BINDER PITCH

DOE Grant Number: ICCI Project Number: Principal Investigator:

Project Manager:
$\mathrm{DE}-\mathrm{FC} 22-92 \mathrm{PC} 92521$ (Year 2)

$93-1 / 1.3 A-3 \mathrm{M}$

Richard A. Knight, Institute of Gas Technology

Dan Banerjee, Illinois Clean Coal Institute

COMMENTS

No changes were made to budget or management in the first quarter 
Projected and Estimated Actual Expenditures by Quarter

UPGRADING MILD GASIFICATION LIQUIDS TO PRODUCE ELECTRODE BINDER PITCH

\begin{tabular}{|c|c|c|c|c|c|c|c|c|c|}
\hline Quarter & $\begin{array}{c}\text { Types of } \\
\text { Cost }\end{array}$ & $\begin{array}{l}\text { Direct } \\
\text { Labor }\end{array}$ & $\begin{array}{l}\text { Fringe } \\
\text { Benefits }\end{array}$ & $\begin{array}{c}\text { Materials } \\
\& \\
\text { Supplies }\end{array}$ & Travel & $\begin{array}{c}\text { Major } \\
\text { Equipment }\end{array}$ & $\begin{array}{l}\text { Other } \\
\text { Direct } \\
\text { Costs }\end{array}$ & $\begin{array}{l}\text { Indirect } \\
\text { Costs }\end{array}$ & Total \\
\hline \multirow{2}{*}{$\begin{array}{l}\text { Sept } 1,1993 \\
\text { to } \\
\text { Nov } 30,1993\end{array}$} & Projected & 9,414 & & 350 & & 5,091 & & 17,742 & 32,597 \\
\hline & Estimated & 5,861 & & 447 & & 5,040 & & 11,506 & 22,854 \\
\hline \multirow{2}{*}{$\begin{array}{c}\text { Sept 1, } 1993 \\
\text { to } \\
\text { Feb 28, } 1994\end{array}$} & Projected & 18,828 & & 1,850 & & 5,091 & & 34,617 & 60,386 \\
\hline & Estimated & & & & & & & & \\
\hline \multirow{2}{*}{$\begin{array}{l}\text { Sept 1, } 1993 \\
\text { to } \\
\text { May 31, } 1994\end{array}$} & Projected & 36,666 & & 3,300 & & 5,091 & & 66,281 & 111,338 \\
\hline & Estimated & & & & & & & & \\
\hline \multirow{2}{*}{$\begin{array}{r}\text { Sept } 1,1993 \\
\text { to } \\
\text { Aug } 31,1994\end{array}$} & Projected & 46,336 & & 3,559 & 260 & 5,091 & & 83,381 & 138,627 \\
\hline & Estimated & & & & & & & & \\
\hline
\end{tabular}

* Cumulative by Quarter 
COSTS BY QUARTER

UPGRADING MILD GASIFICATION LIQUIDS TO PRODUCE E.LECTRODE BINDER PITCH

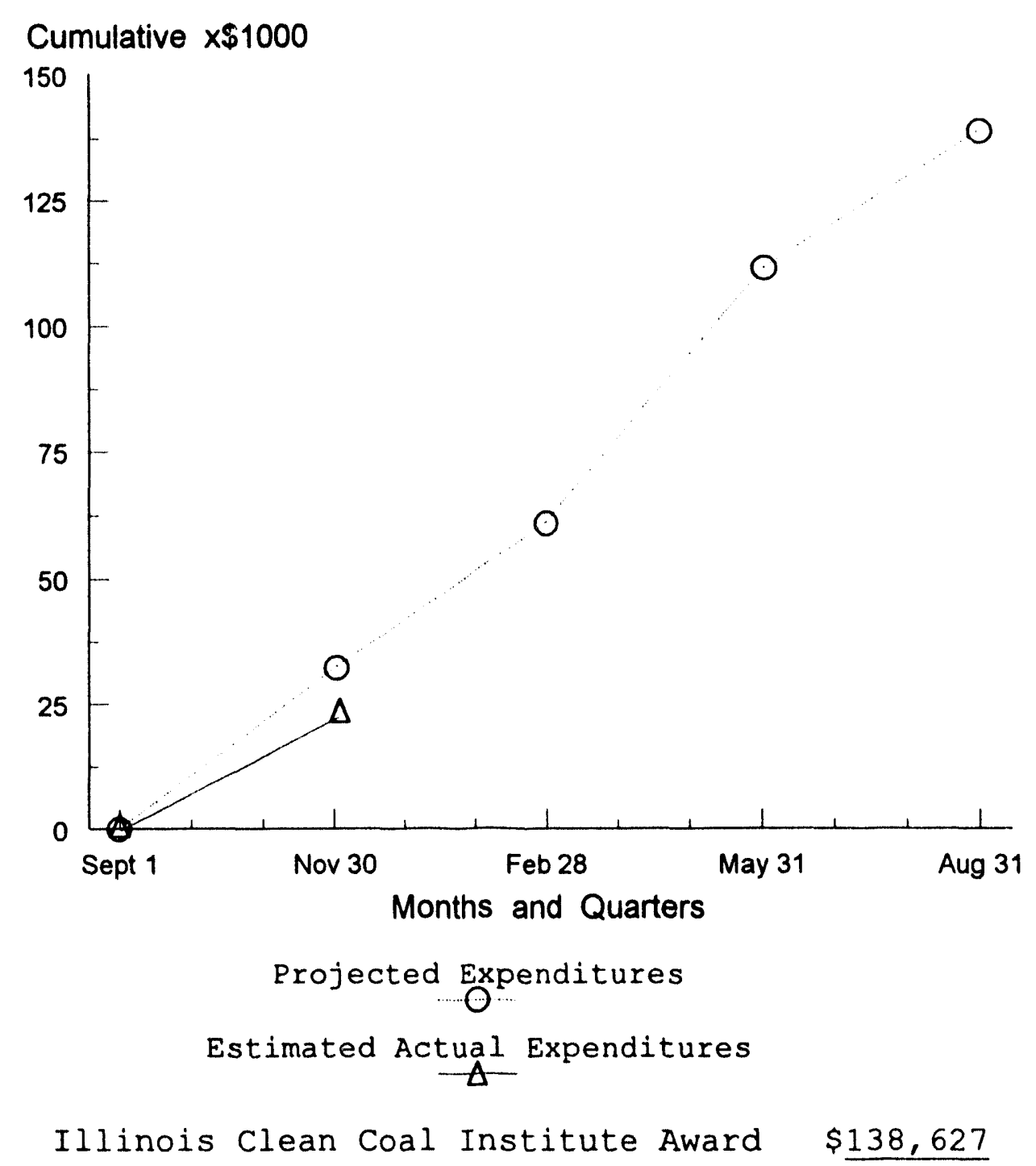




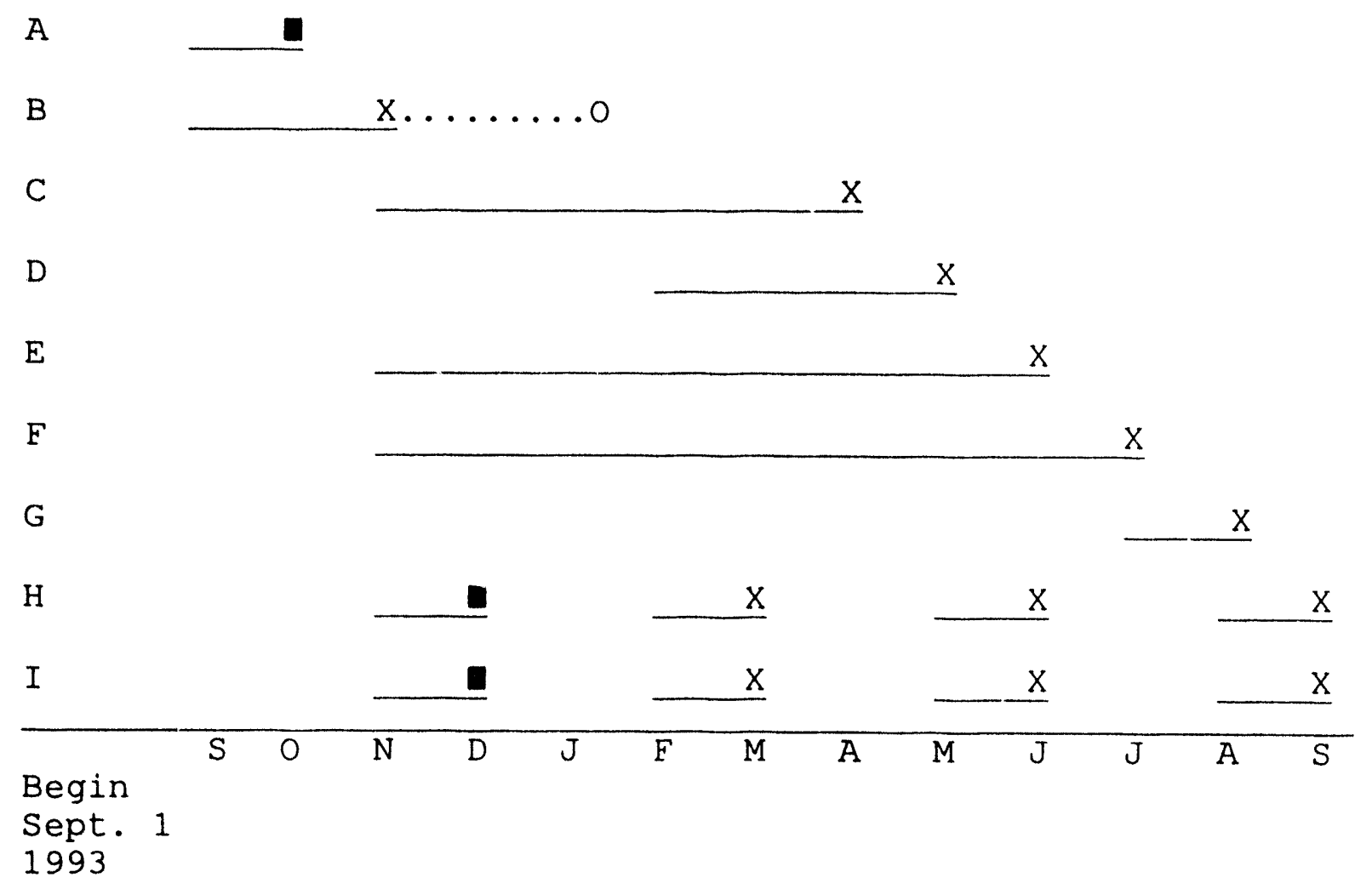

Hypothetical Milestones:

A. MILDGAS crude pitch sample prepared and character zed (Task 1)

B. Modifications and shakedown of thermocracking unit complete (Task 2)

C. Pitch cracking tests completed (Task 3)

D. Test electrodes prepared and tested (Task 4)

E. Product characterization and testing completed (Task 5)

F. Data analysis and interpretation completed (Task 6)

G. Process block flow diagram completed (Task 7)

H. Quarterly and annual technical reports prepared and submitted

I. Quarterly project management reports prepared and submitted

Comment.s:

Completion of Task 2 (Modification and shakedown of thermocracking unit) has been rescheduled for January 1994. 
11
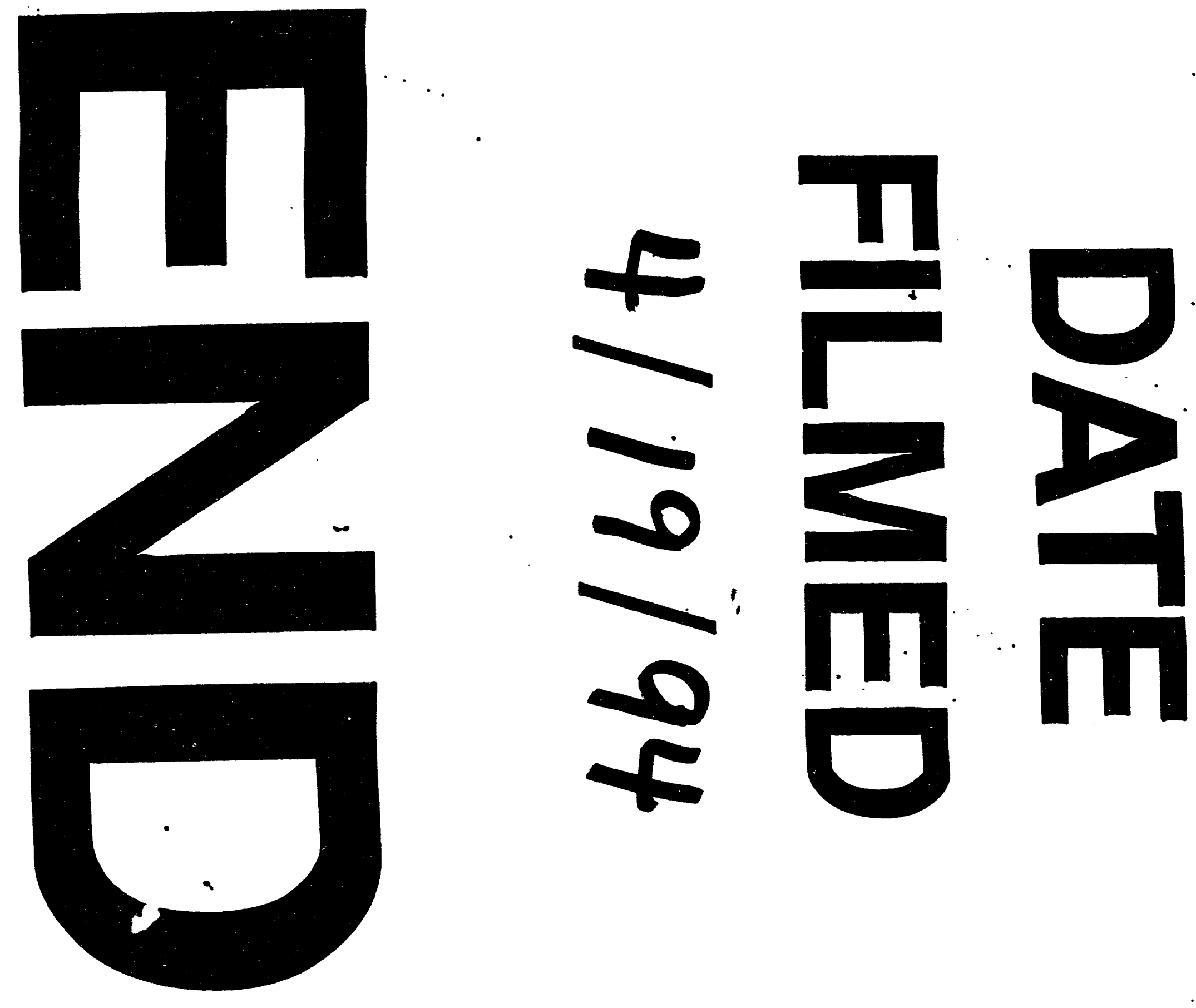


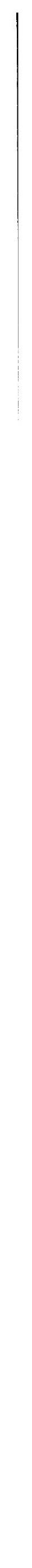

